\title{
Prevalence and molecular characterization of canine and feline hemotropic mycoplasmas (hemoplasmas) in northern Italy
}

Silvia Ravagnan ${ }^{1 *}$, Erika Carli ${ }^{1}$, Eleonora Piseddu², Graziana Da Rold ${ }^{1}$, Elena Porcellato ${ }^{1}$, Claudia Zanardello ${ }^{1}$ Antonio Carminato ${ }^{3}$, Marta Vascellari ${ }^{1}$ and Gioia Capelli ${ }^{1}$

\begin{abstract}
Background: Hemotropic mycoplasmas (hemoplasmas), the agents of infectious anemia, have been reported in dogs and cats. Little data are available on hemoplasma infections in Italy. The aim of this study was to evaluate the species of hemoplasmas and their prevalence in dogs and cats of northern Italy.

Methods: Blood samples were obtained from 117 candidate blood donor dogs, 278 free-roaming dogs and 227 free-roaming cats in 2014 and 2015. Samples were first screened for hemoplasmas with a SYBR green real time PCR. The positive samples were confirmed by a second SYBR green real time PCR and sequencing. Co-infections were detected using species-specific SYBR green real time PCR.

Results: The overall prevalence in dogs was 4.5\% (18/395). Among the donors only one dog was positive for Mycoplasma haemocanis (0.8\%). The overall prevalence of infection in free-roaming dogs was $6.1 \%(17 / 278)$, which was significantly higher than in candidate donors $(P<0.05)$. Both $M$. haemocanis $(13 / 278 ; 4.7 \%)$ and "Candidatus M. haematoparvum" $(4 / 278 ; 1.4 \%)$ were identified. In dogs, no significant association was found between hemoplasma infection and gender, age or origin. The overall prevalence in cats was 13.2\% (30/227). All three feline hemoplasma species were detected, i.e. "Candidatus Mycoplasma haemominutum" (28; 12.3\%), "Candidatus Mycoplasma turicensis" $(11 ; 4.8 \%)$ and Mycoplasma haemofelis $(9 ; 4.0 \%)$. Half of the infected cats were co-infected $(15 ; 6.6 \%)$ with different species of hemoplasmas. Risk factor analysis confirmed that older age, male gender and FIV positivity are predisposing factors for hemoplasma infection in cats.

Conclusion: This study found that candidate blood donor dogs in northern Italy show a negligible risk for hemoplasma infection, confirming the appropriateness of the candidate selection criteria and the low prevalence in the study area. Accordingly, testing for hemoplasma should be considered optional for canine blood donor screening. Hemoplasma infection was instead common in free-roaming cats, and is expected to be non-negligible in owned cats with outdoor access. Feline candidates for blood donation will therefore need to be carefully selected.
\end{abstract}

Keywords: Hemotropic mycoplasmas, Hemoplasmas, Dogs, Cats, Molecular characterization, Northern Italy

\footnotetext{
* Correspondence: sravagnan@izsvenezie.it

'Istituto Zooprofilattico Sperimentale delle Venezie, Legnaro, Padua, Italy

Full list of author information is available at the end of the article
} 


\section{Background}

Hemotropic mycoplasmas (hemoplasmas) are small epicellular parasites that adhere to the erythrocytes of infected animals. They are the causative agents of infectious anemia in several mammalian species, including dogs and cats. Transmission can occur via infected blood, as through blood transfusion, and aggressive interactions. Blood-sucking arthropods like fleas and ticks have also been suggested to be possible vectors, but their ability to transmit the infection has not yet been experimentally confirmed. A role for mites in mechanical transmission of infection has been proposed for dogs [1]. The clinical picture can range from asymptomatic infection to acute hemolytic anemia and can induce anorexia, lethargy, dehydration, weight loss and sudden death [1].

Different species of hemoplasma have been described affecting wild and domestic animals worldwide. Two different species are recognized in dogs: Mycoplasma haemocanis (Mhc) and "Candidatus Mycoplasma haematoparvum" ("CMhp") [2, 3]. Three hemoplasma species are recognized in cats: Mycoplasma haemofelis (Mhf) [4], "Candidatus Mycoplasma haemominutum" ("CMhm") [5] and "Candidatus Mycoplasma turicensis" ("CMt”) [6, 7].

Recently, "CMhm" and "CMt" were detected in dogs in Japan [8] and Chile [9], respectively and "Candidatus Mycoplasma haematoparvum-like" was found in cats in Portugal [10], California [11] and Chile [12].

Little data are available on hemoplasma infections in dogs and cats in Italy. The prevalence of infection in dogs with different lifestyles (kennel and owned dogs), sampled in three cities throughout the country, was $7.5 \%$ in Northern Italy, 9.5\% in Central Italy and $11.5 \%$ in Sicily [13]. In northern Italy, the overall prevalence of hemoplasma infection was $18.9 \%$ in owned cats sampled at a veterinary clinic [14] and $33.1 \%$ in cats living in colonies [15]. In southern Italy, owned cats with a predominantly outdoor lifestyle showed a prevalence of $26.2 \%$ [16].

The aim of this study was to evaluate the species of hemoplasmas and their prevalence in owned dogs and free-roaming dogs and cats of northern Italy. These data are also required to better guide the molecular screening of canine candidate blood donors.

\section{Methods}

\section{Recruitment and data collection}

Overall 622 blood samples were collected in EDTA, from 117 owned candidate blood donor dogs (CBDs), 278 free-roaming dogs (FRDs) and 227 free-roaming cats (FRCs) in 2014 and 2015.

The CBDs fulfilled the following inclusion criteria: age $2-8$ years, body weight $\geq 25 \mathrm{~kg}$, clinically healthy, regularly vaccinated and protected against endo- and ectoparasites. The CBDs came from several municipalities of northern and north-eastern Italian provinces (Padua, Treviso, Verona, Venice, Milan and Bologna).

The FRDs came from two shelters in the provinces of Treviso and Padua. At entry into the shelters they were sampled and clinically evaluated by the local veterinary health units, in the framework of a zoonotic agent control and staff protection program. The FRDs included in this study had no apparent clinical signs.

The FRCs had been rescued and were based at a single cat shelter (Novara Province), where they had outdoor access in a confined environment. They underwent clinical evaluation and blood sampling during sterilization.

All blood samples were then submitted to the IDEXX Laboratories (Novara, Italy) for a complete cell blood count and evaluation of the cats' FIV/FeLV status (feline immunodeficiency virus/feline leukemia virus) by the SNAP $^{\oplus}$ FIV/FeLV Combo test (IDEXX Laboratories, Westbrook, ME-USA). The sensitivity and specificity of the Snap test were reported to be: FIV (93.5-100\%) and FeLV (98.6-98.2\%). Anemia was defined as a deficiency of red blood cells $(<5 \mathrm{M} / \mu \mathrm{l}$ in cats and $5.3 \mathrm{M} / \mu \mathrm{l}$ in dogs) or of hemoglobin in the blood $(<9 \mathrm{~g} / \mathrm{dl}$ in cats and $13 \mathrm{~g} / \mathrm{dl}$ in dogs). No other information was available. An aliquot of each sample was frozen at $-20{ }^{\circ} \mathrm{C}$ and stored until DNA extraction.

Based on clinical evaluation and blood test results, 170 cats were classified as healthy, the remaining were anemic and/or positive to FIV/FeLV.

\section{Molecular analysis}

To detect and characterize hemoplasma infections in cats and dogs we used the following approach: (i) a first screening was performed using a sensitive SYBR green real time PCR (rPCR) (16S rRNA gene) to select positive samples of known and unknown species; (ii) the positive samples underwent a second SYBR green rPCR (16S rRNA gene) to amplify a longer PCR product suitable for sequencing and species identification; (iii) a SYBR green rPCR targeting the RNaseP gene was used to distinguish between Mhf and Mhc species; and (iv) speciesspecific rPCRs (16S rRNA gene) were applied to positive samples to detect co-infections.

\section{Nucleic acid extraction and internal control}

DNA was extracted from $100 \mu \mathrm{l}$ of EDTA-blood samples using a DNeasy Blood \& Tissue kit (Qiagen, Valencia, CA, USA), according to the manufacturer's instructions. The DNA was eluted in $200 \mu$ l elution buffer and stored at $-20{ }^{\circ} \mathrm{C}$ until use. A negative control (PBS) was used in parallel with the extraction of each set of samples. Before screening the hemoplasmas, all the samples were amplified using a traditional PCR targeting the $18 \mathrm{~S}$ rRNA internal control, to ensure the effectiveness of the nucleic acid extraction [17]. 


\section{Screening}

Samples were screened using a SYBR green rPCR, performed with the primers Mycf (5' $5^{\prime}$ AGC AAT RCC ATG TGA ACG ATG AA-3') and MycR1 (5'-TGG CAC ATA GTT TGC TGT CAC TT-3'), as previously described [18]. The reactions were carried out in a total volume of $20 \mu \mathrm{l}$, containing $10 \mu \mathrm{l}$ of QuantiFast SYBR Green PCR Master mix 2× (Qiagen GmbH, Germany), $0.1 \mu \mathrm{M}$ of sense and reverse primer and $3 \mu \mathrm{l}$ of extracted DNA. Amplifications were performed in a StepOnePlus ${ }^{\text {тM }}$ instrument (Applied Biosystems, Foster City, CA). The thermal profile consisted of $5 \mathrm{~min}$ at $95{ }^{\circ} \mathrm{C}$, followed by 40 cycles at $95{ }^{\circ} \mathrm{C}$ for $15 \mathrm{~s}, 62{ }^{\circ} \mathrm{C}$ for $30 \mathrm{~s}$ and $60{ }^{\circ} \mathrm{C}$ for 30 s. Following amplification, dissociation was performed by slowly raising the temperature of the thermal chamber from 60 to $95{ }^{\circ} \mathrm{C}$. Negative (sterile water) and positive controls (DNA of $\mathrm{Mhc}$ ) were included in each run.

\section{Hemoplasma species identification}

Since the amplicon produced by the screening rPCR was too short (127 bp) for good species identification [18], all hemoplasma-positive samples were amplified using a newly designed SYBR green rPCR based on conserved regions of the 16S rRNA gene (MycE929f: $5^{\prime}$-ACG GGG ACC TGA ACA AGT GGT G-3' and MycE1182r: 5'AGG CAT AAG GGG CAT GAT GAC TTG-3'). This PCR was designed to amplify a $259 \mathrm{bp}$ PCR product, to allow species identification following sequencing.

The reactions were carried out in a total volume of $20 \mu \mathrm{l}$, containing $10 \mu \mathrm{l}$ of QuantiFast SYBR Green PCR Master mix 2× (Qiagen $\mathrm{GmbH}$, Germany), $0.1 \mu \mathrm{M}$ of sense and reverse primer (MycE929f - MycE1182r) and $3 \mu \mathrm{l}$ of extracted DNA. Amplifications were performed in a StepOnePlus ${ }^{\mathrm{TM}}$ instrument (Applied Biosystems, Foster City, CA, USA). The thermal profile consisted of $5 \mathrm{~min}$ at $95{ }^{\circ} \mathrm{C}$, followed by 40 cycles at $95{ }^{\circ} \mathrm{C}$ for $15 \mathrm{~s}, 60{ }^{\circ} \mathrm{C}$ for $30 \mathrm{~s}$ and $60{ }^{\circ} \mathrm{C}$ for $30 \mathrm{~s}$. Following amplification, melting curve analysis was performed by slowly raising the temperature of the thermal chamber from 60 to $95{ }^{\circ} \mathrm{C}$ to distinguish between hemoplasma amplicons (Tm range 76.2-77.3 ${ }^{\circ} \mathrm{C}$ ) and non-specific amplification products. Negative (sterile water) and positive controls (DNA of Mhc) were included in each run.

The sensitivity of this rPCR was determined using synthetic DNA of Mhc. After spectrophotometrically determining the concentration, the plasmid DNA copy numbers were calculated with the formula: $\mathrm{Y}=\mathrm{X} /(\mathrm{a} \times 660) \times 6.022 \times$ $10^{23}$, where: $\mathrm{Y}=$ molecules $/ \mu \mathrm{l} ; \mathrm{X}=\mathrm{g} / \mu \mathrm{l}$ dsDNA; $\mathrm{a}=$ plasmid plus insert length in nucleotides; 660 is the average molecular weight per nucleotide of dsDNA. The detection limit, evaluated using 10-fold serial dilutions of synthetic DNA, tested in triplicate, was $10^{1} \mathrm{DNA}$ copies/rPCR. The inclusivity of the assay was confirmed by analyzing canine and feline hemoplasma reference strains of Mhc, "CMhp", Mhf, "CMhm" and "CMt".

In addition, since the $16 \mathrm{~S}$ rRNA gene sequence is identical for Mhf and Mhc, the positive samples of these two species were amplified, using the RNase $\mathrm{P}$ gene primers RNasePFor1 and RNasePrev1, which more reliably differentiate between the two species, and sequenced [19]. The reactions were carried out in a total volume of $20 \mu \mathrm{l}$, containing $10 \mu \mathrm{l}$ of QuantiFast SYBR Green PCR Master mix 2× (Qiagen $\mathrm{GmbH}$, Germany), $0.1 \mu \mathrm{M}$ of sense and reverse primer and $3 \mu \mathrm{l}$ of extracted DNA. Amplifications were performed in a StepOnePlus ${ }^{\mathrm{TM}}$ instrument (Applied Biosystems, Foster City, CA, USA). The thermal profile consisted of $5 \mathrm{~min}$ at $95{ }^{\circ} \mathrm{C}$, followed by $40 \mathrm{cy}$ cles at $95{ }^{\circ} \mathrm{C}$ for $15 \mathrm{~s}, 58^{\circ} \mathrm{C}$ for $30 \mathrm{~s}$ and $60{ }^{\circ} \mathrm{C}$ for $30 \mathrm{~s}$. Following amplification, dissociation was performed by slowly raising the temperature of the thermal chamber from 60 to $95{ }^{\circ} \mathrm{C}$. Negative (sterile water) and positive controls (DNA of Mhc and Mhf) were included in each run.

The PCR products obtained with $16 \mathrm{~S}$ rRNA and the RNase P gene were directly sequenced. Sequencing was performed with 16S rRNA gene primers MycE929f and MycE1182r and with RNase P gene primers RNasePFor1 and RNasePrev1, using the Big Dye Terminator v3.1 cycle sequencing kit (Applied Biosystems, Foster City, CA, USA). The products were purified using the PERFORMA DTR Ultra 96-Well kit (Edge BioSystems, Gaithersburg, MD, USA) and sequenced in a 16-capillary ABI PRISM 3130xl Genetic Analyzer (Applied Biosystems, Foster City, CA, USA). Sequence data were assembled and edited with SeqScape software v2.5 (Applied Biosystems, Foster City, CA, USA). The sequence data were compared with representative sequences available in GenBank, using the Basic Local Alignment Search Tool (BLAST) [20] to identify hemoplasma species.

\section{Co-infections}

Finally, species-specific real time PCRs were applied to positive samples to detect co-infections, using forward primer "Mycoplasma species-F" coupled with four reverse primers specific for Mhf/Mhc, CMhm, CMhp and CMt ("Mycoplasma haemofelis-R", "Candidatus Mycoplasma haemominutum-R”, "Candidatus Mycoplasma haematoparvum-R", "Candidatus Mycoplasma turicensis-R", respectively), applying a previously described method and conditions [11].

\section{Statistical analysis}

Differences in hemoplasma prevalence between animal populations stratified by age, gender, lifestyle (FRDs $v s$ donors, in the case of dogs) and age, gender, anemic status and FIV or FeLV test results (in the case of cats), were first tested for statistical significance through 
Table 1 Prevalence of hemoplasmas in 278 free-roaming dogs of Northern Italy. No significant differences were found

\begin{tabular}{|c|c|c|c|c|c|}
\hline Variables & & No. of dogs & Hemoplasma (\%) & $\begin{array}{l}\text { Mhc } \\
(\%)\end{array}$ & $\begin{array}{l}\text { "CMhp" } \\
(\%)\end{array}$ \\
\hline \multirow[t]{2}{*}{ Gender } & Female & 78 & $5(6.4)$ & $2(2.6)$ & $3(3.8)$ \\
\hline & Male & 196 & $11(5.6)$ & $10(5.1)$ & $1(0.5)$ \\
\hline \multirow[t]{2}{*}{$\mathrm{Age}^{\mathrm{a}}$} & young $(\leq 1$ year) & 56 & $1(1.8)$ & $1(1.8)$ & $0(0.0)$ \\
\hline & adult (> 1 year) & 99 & $2(2.0)$ & $1(1.0)$ & $1(1.0)$ \\
\hline \multirow[t]{2}{*}{ Province } & Padua & 112 & $4(3.6)$ & $2(1.8)$ & $2(1.8)$ \\
\hline & Treviso & 166 & $13(7.8)$ & $11(6.6)$ & $2(1.2)$ \\
\hline
\end{tabular}

${ }^{a}$ Estimated age available only for dogs from the Padua shelter

Abbreviations: Mhc Mycoplasma haemocanis, "CMhp" "Candidatus Mycoplasma haematoparvum"

univariate analysis, using the Chi-square test or Fisher's exact test, where appropriate.

The variables significantly associated with hemoplasma infection in the univariate testing were analysed by means of logistic regression models to evaluate potential risk factors associated with hemoplasma prevalence [21]. In logistic regression, the hemoplasma infection represented the dependent variable and the animal's features represented the independent variables. The variable "age" was coded as 0 for young (up to one year) and 1 for adults; "gender" was coded as 0 for female and 1 for male; "FIV/FeLV" was coded as 0 for negative and 1 for positive, and "anemia" was coded as 0 for non-anemic and 1 for anemic cat. Collinearity among independent variables was controlled using the Pearson correlation coefficient. The significance was set at $P<0.05$. The software used was SPSS for Windows, version 13.0.

\section{Results}

The overall prevalence of hemoplasma infection in dogs was $4.5 \%$ (18/395). Only one CBD was positive for Mhc (1/117; $0.8 \%)$. The prevalence of hemoplasma infection among FRDs was 6.1\% $(17 / 278)$ and both Mhc $(13 / 278$; $4.7 \%)$ and "CMhp" $(4 / 278 ; 1.4 \%)$ were identified.
Neither co-infections nor hemoplasma species typical of cats were detected in dogs. The prevalence of hemoplasmas was significantly higher in FRDs compared to CBDs $\left(\chi^{2}=7.423, d f=1, P=0.0064\right)$. Among FRDs, no differences were observed in the prevalence of hemoplasma infection by age group, gender and province of origin (Table 1). The overall prevalence of infection in cats was $13.2 \%(30 / 227)$. All three species affecting cats were found, i.e. "CMhm" (28/227; 12.3\%), "CMt" (11/ 227; $4.8 \%)$, and $\operatorname{Mhf}(9 / 227 ; 4.0 \%)$. Half of the positive cats were co-infected $(15 / 227 ; 6.6 \%)$ with different species of hemoplasmas, i.e. 12 showed double co-infections (eight "CMhm"/Mhf and four "CMhm"/"CMt") and three had triple co-infections. Hemoplasma species typical of dogs were not found in cats.

Hemoplasma-infected cats were more likely to be males $\left(\chi^{2}=12.404, d f=1, P<0.0001\right)$ and to be older than 1 year of age $\left(\chi^{2}=24.944, d f=1, P<0.0001\right)$ (Table 2$)$. The prevalence of hemoplasmas was significantly higher in FIV-positive cats $(65.2 \%$ vs $7.4 \%)\left(\chi^{2}=54.063, d f=1\right.$, $P<0.0001)$, but not in FeLV-positive felines, and was also significantly higher in anemic cats $(25.8$ vs $11.2 \%$; $X^{2}=4.962, d f=1, P=0.026$ ) (Table 2). Regarding the prevalence of hemoplasmas in anemic cats stratified by

Table 2 Prevalence of hemoplasmas in 227 cats from northern Italy (Novara Province). Significant differences are marked with equal letters (uppercase, $P<0.01$; lowercase, $P<0.05$ )

\begin{tabular}{|c|c|c|c|c|c|c|}
\hline Variables & & No. of dogs & Hemoplasma (\%) & "CMhm" (\%) & Mhf (\%) & "CMt" (\%) \\
\hline \multirow[t]{2}{*}{ Gender } & Female & 119 & $3(2.5)^{\mathrm{A}}$ & $3(2.5)^{B}$ & $0(0.0)^{C}$ & $0(0.0)^{\mathrm{D}}$ \\
\hline & Male & 108 & $27(25.0)^{\mathrm{A}}$ & $25(23.1)^{B}$ & $9(8.3)^{C}$ & $11(10.2)^{D}$ \\
\hline \multirow[t]{2}{*}{ Age } & Young $(\leq 1$ year $)$ & 120 & $7(5.8)^{\mathrm{E}}$ & $7(5.8)^{F}$ & $3(2.5)$ & $2(1.7)^{\mathrm{g}}$ \\
\hline & Adult (> 1 year) & 101 & $22(21.8)^{\mathrm{E}}$ & $20(19.8)^{F}$ & $6(5.9)$ & $8(7.9)^{9}$ \\
\hline \multirow[t]{2}{*}{ Anemia } & Yes & 31 & $8(25.8)^{h}$ & $7(22.6)$ & $4(12.9)^{i}$ & $3(9.7)$ \\
\hline & No & 196 & $22(11.2)^{\mathrm{h}}$ & $21(10.7)$ & $5(2.5)^{i}$ & $8(4.1)$ \\
\hline \multirow[t]{2}{*}{ FIV } & Positive & 23 & $15(65.2)^{L}$ & $13(56.5)^{\mathrm{M}}$ & $7(30.4)^{N}$ & $7(30.4)^{O}$ \\
\hline & Negative & 204 & $15(7.4)^{\mathrm{L}}$ & $15(7.4)^{\mathrm{M}}$ & $2(1.0)^{\mathrm{N}}$ & $4(2.0)^{\mathrm{O}}$ \\
\hline \multirow[t]{2}{*}{ FeLV } & Positive & 13 & $2(15.4)$ & $2(15.4)$ & $1(7.7)$ & $0(0.0)$ \\
\hline & Negative & 214 & 28 (13.1) & $26(12.1)$ & $7(3.3)$ & $11(5.1)$ \\
\hline
\end{tabular}

Abbreviations: "CMhm"'"Candidatus Mycoplasma haemominutum", Mhf Mycoplasma haemofelis, "CMt" "Candidatus Mycoplasma turicensis", no number 
Mycoplasma species, only anemic cats infected by the Mhf species were significantly more positive than healthy cats (12.9 vs $\left.2.5 \% ; \chi^{2}=5.060, d f=1, P=0.0245\right)$. Multivariate analysis confirmed male gender $(\mathrm{OR}=$ $13.168)$, older age $(\mathrm{OR}=3.666)$ and FIV positivity (OR $=13.859$ ) to be risk factors (Table 3 ).

\section{Discussion}

This study highlights that most of the known species of hemoplasmas of dogs and cats are present in northern Italy. The overall prevalence of hemoplasmas in our dogs $(4.5 \%)$ and cats $(13.2 \%)$ is comparable with several previous studies. One study on canine hemoplasmas in 600 dogs from northern, central and southern Italy showed prevalences of $7.5,9.5$ and $11.5 \%$, respectively [13]. Studies performed in owned cats from veterinary clinics reported prevalence rates of $18.9 \%(n=307)$ in northern Italy [14] and $26.2 \%(n=42)$ in southern Italy [16]. A much higher prevalence of $31.3 \%$ was found in 206 cats from colonies of Milan, in north-western Italy [15]. This rate was also higher than the majority of other studies performed in Europe and the authors attributed the difference to the type of population sampled (stray colony cats), which presented several risk factors simultaneously, i.e. a high percentage of unhealthy cats (including anemia, FIV positivity and other clinical/pathological abnormalities), a higher probability of aggressive interactions in colonies, and abundant flea populations.

Other studies performed in Europe revealed a marked difference in prevalence among countries. The prevalence ranged from 1.2 to $40 \%$ in dogs (Table 4) and from 9 to $43.3 \%$ in cats (Table 5). This is likely due to several factors, i.e. the sampled populations, geographical variations and the different diagnostic techniques used, from microscopic examination to molecular detection.

Our study showed that free-roaming dogs were more frequently infected than candidate blood donors, in which the prevalence of hemoplasmas was negligible. This finding is most likely explained by the regular use of compounds against arthropod vectors and greater owner care. Living in kennels was in fact found to be a risk factor in dogs from Mediterranean countries [13]. No association between hemoplasma prevalence and
Table 4 Percentage of animals PCR-positive for canine hemoplasma in the sampled populations of Europe

\begin{tabular}{llllll}
\hline Country & $\begin{array}{l}\text { Hemoplasma } \\
(\%)\end{array}$ & $\begin{array}{l}\text { Mhc } \\
(\%)\end{array}$ & $\begin{array}{l}\text { "CMhp" } \\
(\%)\end{array}$ & $\begin{array}{l}\text { Co-infected } \\
(\%)\end{array}$ & Reference \\
\hline Switzerland & 1.2 & 0.9 & 0.3 & 0 & {$[30]$} \\
Spain & $2.5-14.3$ & $0.5-14.3$ & $0.6-2$ & $0-0.6$ & {$[13,31]$} \\
Portugal & 40.0 & 40.0 & 0 & 0 & {$[13]$} \\
France & 15.4 & 5.8 & 12.2 & 2.6 & {$[32]$} \\
Italy & 9.5 & 4.5 & 5.8 & 0.8 & {$[13]$} \\
\hline
\end{tabular}

Abbreviations: Mhc Mycoplasma haemocanis, "CMhp" "Candidatus Mycoplasma haematoparvum"

other potential risk factors was found in the dogs studied by us (Table 1), in accordance with a recent study [22] that in addition found no association with breed, clinical status, tick presence, ectoparasite prophylaxis and anemia. In other studies, young and male dogs seemed to be more susceptible to canine hemoplasma infections [13, 23]. Other risk factors could include cross-breeding and mange infection [11], presence of vectors, older age, dog bite wounds, neoplastic diseases, dogs of rural $v s$ urban localities [9, 24]. This heterogeneity of results in respect to possible risk factors for hemoplasma infection in dogs may reflect the presence of confounding factors or weak associations.

Our study confirmed that "CMhm" is the prevalent species in cats and that co-infection is frequent. The different feline hemoplasma species have different pathogenic potential. Mhf was found to be more pathogenic than "CMhm" $[25,26]$, while "CMt" could induce mild to moderate anemia $[6,27,28]$. In our study "CMhm" was more prevalent in cats with anemia compared to other species, but only Mhf was found to be significantly more represented in anemic compared to healthy cats, confirming the above studies. Anemia did not arise as a risk factor for hemoplasma infection, but this is consistent with the fact that anemia is a consequence of the infection (at least in the case of Mhf and "CMt") rather than a predisposing factor.

In our cats, male gender, adult age and FIV positivity were found to be risk factors for hemoplasma infection, confirming several other studies [1, 6, 12, 13, 22, 27-29]. The authors concur in explaining the reasons for these associations, i.e. (i) male cats, especially if they are not

Table 3 Results of the multivariate analysis for potential risk factors in cats

\begin{tabular}{llllllcc}
\hline Independent variables & $\mathrm{B}$ & $\mathrm{SE}$ & Wald & $\mathrm{df}$ & $\mathrm{P}$ & Exp(B) (Odds ratio) & 95\% Cl for Exp(B) \\
\hline Age & 1.299 & 0.561 & 5.371 & 1 & 0.020 & 3.666 & $1.222-10.996$ \\
Gender & 2.578 & 0.698 & 13.637 & 1 & 0.000 & 13.168 & $3.352-51.725$ \\
FIV & 2.629 & 0.644 & 16.690 & 1 & 0.000 & 13.859 & $3.926-48.921$ \\
FELV & 1.521 & 1.169 & 1.692 & 1 & 0.193 & 4.577 & $0.463-45.292$ \\
Anemia & 0.081 & 0.717 & 0.013 & 1 & 0.910 & 1.085 & $0.266-4.422$ \\
Constant & -5.018 & 0.802 & 39.139 & 1 & 0.000 & 0.007 & \\
\hline
\end{tabular}


Table 5 Percentage of animals that were PCR-positive for feline hemoplasma in the sampled populations of Europe

\begin{tabular}{|c|c|c|c|c|c|c|}
\hline Country & Hemoplasma (\%) & "CMhm" (\%) & $\operatorname{Mhf}(\%)$ & "CMt" (\%) & Co-infected (\%) & Reference \\
\hline Switzerland & 9.0 & 8.5 & 0.5 & 1.0 & 1.0 & {$[7]$} \\
\hline Germany & $15.5-27.8$ & 8.9-23.3 & $5.3-7.4$ & 2.2 & $0.8-3.0$ & {$[33,34]$} \\
\hline UK & $14.1-18.5$ & $11.2-17.1$ & $1.6-2.8$ & $1.7-2.3$ & $1.6-1.9$ & {$[35,36]$} \\
\hline Spain & $12.1-30.0$ & 7.9-10.0 & $2.1-20.0$ & 0.5 & 2.0 & {$[31,37]$} \\
\hline Portugal & $27.1-43.3$ & $17.8-41.6$ & $12.8-14.4$ & $1.2-5.8$ & $8.1-13.0$ & {$[11,29]$} \\
\hline Albania & 30.8 & 21.9 & 10.3 & 5.5 & 6.8 & [38] \\
\hline Italy & $18.9-33.1-26.2$ & $17.3-22.3-16.7$ & $5.9-10.8-16.7$ & $1.3-\mathrm{nt}-9.5$ & $5.5-\mathrm{nt}-\mathrm{nt}$ & [14-16] \\
\hline
\end{tabular}

Abbreviations: "CMhm" "Candidatus Mycoplasma haemominutum", Mhf Mycoplasma haemofelis, "CMt" "Candidatus Mycoplasma turicensis"; nt not tested

neutered, have more aggressive interactions which may enhance transmission via infected blood; (ii) adult animals have been exposed to blood-sucking arthropods for longer and also have more aggressive interactions; and (iii) FIV positivity is associated with an immune-suppression status. However, FIV positivity and hemoplasma infection may be related simply because they share the same route of transmission through bite wounds.

The molecular protocol used in our study was suitable for the identification of all five species of hemoplasmas in both dogs and cats and can be applied to both the diagnosis and screening of blood donors.

\section{Conclusions}

This study found that canine candidate blood donors in northern Italy showed a negligible risk for hemoplasma infections, confirming the appropriateness of candidate selection criteria and the low prevalence in the study area. Accordingly, testing for hemoplasma should be considered optional for the screening of canine blood donors in this epidemiological setting. By contrast, our results confirmed that hemoplasma infection is a common finding in cattery cats of northern Italy. Cats will therefore need to be carefully selected as candidate blood donors, since owned cats frequently have outdoor access and may show risky behavior.

\section{Abbreviations}

"CMhm": "Candidatus Mycoplasma haemominutum"; "CMhp": "Candidatus Mycoplasma haematoparvum"; "CMt": "Candidatus Mycoplasma turicensis"; CBD: Candidate blood donor; EDTA: Ethylenediaminetetraacetic acid; FRC: Free-roaming cat; FRD: Free-roaming dog; Mhc: Mycoplasma haemocanis; Mhf: Mycoplasma haemofelis; PBS: Phosphate-buffered saline; PCR: Polymerase chain reaction

\footnotetext{
Acknowledgments

The authors are grateful to Alberto Camerini, Riccardo Friso, Alfio Bortolini, Aldo Costa and Giovanni Dal Maso of the Local Veterinary Units for their help in the recruitment of dogs and in sampling. The authors are very grateful to the owners of the dogs for their contribution to canine blood donation, and to Dr. Davide Pozzi, head of the Galliate Cattery (Novara). The authors wish to thank Silvia Ormelli and Sabrina Marciano (Istituto Zooprofilattico Sperimentale delle Venezie) for sequencing the amplicons, and Joanne Fleming for the English revision of the manuscript. The paper has been sponsored by Bayer Animal Health in the framework of the $12^{\text {th }}$ CVBD World Forum Symposium.
}

Funding

This work was supported by a grant from the Italian Ministry of Health (project code RC-IZSVE 03/2013).

\section{Availability of data and materials}

The data supporting the conclusions of this article are included within the article. The raw data used or analyzed during the current study are available from the corresponding author upon reasonable request.

\section{Authors' contributions}

SR and GC conceived the study and wrote the paper; VM and EC designed and coordinated dog and cat recruitment; EC, EP, CZ and AC performed the sampling and clinical evaluation of the dogs and cats; GDR, EPO performed the biomolecular analysis. VM contributed to the Discussion and revised the paper. All authors read and approved the final manuscript.

\section{Competing interests}

The authors declare that they have no competing interests.

\section{Consent for publication}

Not applicable.

\section{Ethics approval and consent to participate}

The animals did not undergo any additional blood sampling for this study. We used an aliquot of blood sampled for other programs described herein. Informed consent was obtained from the owners of CBDs, as required by the Blood Bank to become an eligible donor. The donor screening program requires the acquisition of information on the health history of the dog and previous infectious disease testing. FRDs were sampled at the time of entry into the shelters by official veterinarians of the Local Health Units of Padua and Treviso, under a zoonosis prevention and staff protection program. Cats were sampled to be tested for FIV/FeLV during sterilization by official veterinarians of the Local Health Unit.

\section{Author details}

${ }^{1}$ Istituto Zooprofilattico Sperimentale delle Venezie, Legnaro, Padua, Italy. ${ }^{2}$ IDEXX-Laboratories-Novara Day Lab, Granozzo con Monticello, Novara, Italy.

${ }^{3}$ Practitioner, Camponogara, Venice, Italy.

Received: 18 February 2017 Accepted: 28 February 2017

Published online: 13 March 2017

References

1. Willy B, Novacco M, Meli ML, Wolf-Jackel GA, Boretti FS, Wengi N, et al. Haemotropic mycoplasmas of cats and dogs: trasmission, diagnosias, prevalence and importance in Europe. Schweiz Arch Tierheil. 2010;152(5): 237-44.

2. Messick JB, Walker PG, Raphael W, Berent L, Shi X. 'Candidatus Mycoplasma haemodidelphidis' sp. nov., 'Candidatus Mycoplasma haemolamae' sp. nov. and Mycoplasma haemocanis comb. nov., haemotrophic parasites from a naturally infected opossum (Didelphis virginiana), alpaca (Lama pacos) and dog (Canis familiaris): phylogenetic and secondary structural relatedness of their 165 rRNA genes to other mycoplasmas. Int J Syst Evol Microbiol. 2002; 52(3):693-8. 
3. Sykes JE, Bailiff NL, Ball LM, Foreman O, George JW, Fry MM. Identification of a novel hemotropic mycoplasma in a splenectomized dog with hemic neoplasia. J Am Vete Med Assoc. 2004;224(12):1946-51.

4. Neimark H, Johansson KE, Rikihisa Y, Tully JG. Proposal to transfer some members of the genera Haemobartonella and Eperythrozoon to the genus Mycoplasma with descriptions of 'Candidatus Mycoplasma haemofelis', 'Candidatus Mycoplasma haemomuris', 'Candidatus Mycoplasma haemosuis' and 'Candidatus Mycoplasma wenyonii'. Int J Syst Evol Microbiol. 2001;51(3):891-9.

5. Foley JP, Pedersen NC. 'Candidatus Mycoplasma haemominutum', a low-virulence erpierythrocytic parasite of cats. Int J Syst Evol Microbiol. 2001;51:815-7.

6. Willi B, Boretti F, Cattori V, Tasker S, Meli ML, Reusch C, et al. Identification, molecular characterization, and experimental transmission of a new hemoplasma isolate from a cat with hemolytic anemia in Switzerland. J Clin Microbiol. 2005:43:2581-5.

7. Willi B, Boretti FS, Baumgartner C, Cattori V, Meli ML, Doherr MG, et al. Feline hemoplasmas in Switzerland: identification of a novel species, diagnosis, prevalence, and clinical importance. Schweiz Arch Tierheilk. 2006;148:139-44.

8. Obara H, Fujihara M, Watanabe Y, Ono HK, Harasawa R. A Feline hemoplasma, 'Candidatus Mycoplasma haemominutum', detected in dog in Japan. J Vet Med Sci. 2011;73(6):841-3.

9. Soto F, Walker R, Sepulveda M, Bittencourt P, Acosta-Jamett G, Müller A. Occurrence of canine hemotropic mycoplasmas in domestic dogs from urban and rural areas of the Valdivia Province, southern Chile. Comp Immunol Microbiol Infect Dis. 2017:50:70-7.

10. Sykes JE, Drazenovich NL, Ball LM, Leutenegger CM. Use of conventional and Real-Time polymerase chain reaction to determine the epidemiology of hemoplasma infections in anemic and nonanemic cats. J Vet Int Med. 2007;21(4):685-93.

11. Martínez-Díaz VL, Silvestre-Ferreira AC, Vilhena H, Pastor J, Francino O, Altet L. Prevalence and co-infection of haemotropic mycoplasmas in Portuguese cats by real-time polymerase chain reaction. J Feline Med Surg. 2013; 15(10):879-85

12. Vergara RW, Galleguillos FM, Jaramillo MG, Almosny NRP, Martínez PA, Behne PG, et al. Prevalence, risk factor analysis, and hematological findings of hemoplasma infection in domestic cats from Valdivia, Southern Chile. Comp Immunol Microbiol Infect Dis. 2016;46:20-6.

13. Novacco M, Meli ML, Gentilini F, Marsilio F, Ceci C, Pennisi MG, et al. Prevalence and geographical distribution of canine hemotropic mycoplasma infections in Mediterranean countries and analysis of risk factors for infection. Vet Microbiol. 2010;142(3):276-84.

14. Gentilini F, Novacco M, Turba ME, Willi B, Bacci ML, Hofmann-Lehmann R. Use of combined conventional and real-time PCR to determine the epidemiology of feline haemoplasma infections in northern Italy. J Fel Med Surg. 2009;11(4):277-85.

15. Spada E, Proverbio D, Galluzzo P, Della Pepa A, Bagnagatti De Giorgi G, et al. Prevalence of haemoplasma infections in stray cats in northern Italy. ISRN Microbiol. 2014;2014:298352.

16. Persichetti M, Solano-Gallego L, Serrano L, Altet L, Reale S, Masucci M, et al. Detection of vector-borne pathogens in cats and their ectoparasites in southern Italy. Parasit Vectors. 2016;9:1.

17. Smith J, McElhinney LM, Heaton PR, Black EM, Lowings JP. Assessment of template quality by the incorporation of an internal control into a RT-PCR for the detection of rabies and rabies-related viruses. J Virol Methods. 2000;84(2):107-15

18. Willi B, Meli ML, Lüthy R, Honegger H, Wengi N, Hoelzle LE, et al. Development and application of a universal hemoplasma screening assay based on the SYBR Green PCR principle. J Clin Microb. 2009;47(12):4049-54.

19. Willi B, Filoni C, Catão-Dias JL, Cattori V, Meli ML, Vargas A, et al. Worldwide occurrence of feline hemoplasma infections in wild felid species. J Clin Microb. 2007;45(4):1159-66

20. Altschul SF, Gish W, Miller W, Myers EW, Lipman DJ. Basic local alignment search tool. J Mol Biol. 1990;215(3):403-10.

21. Hosmer DW, Lameshow S. Applied logistic regression. 2nd ed. New York: Wiley; 2000

22. Aquino LC, Hicks CA, Scalon MC, Lima MG, Lemos MD, Paludo GR, et al. Prevalence and phylogenetic analysis of haemoplasmas from cats infected with multiple species. J Microbiol Methods. 2014;107:189-96.

23. Barker EN, Tasker S, Day MJ, Warman SM, Woolley K, Birtles R, et al. Development and use of real-time PCR to detect and quantify Mycoplasma haemocanis and
"Candidatus Mycoplasma haematoparvum" in dogs. Vet Microbiol. 2010; 140(1):167-70.

24. Valle SF, Messick JB, Santos AP, Kreutz LC, Duda NC, Machado G, et al. Identification, occurrence and clinical findings of canine hemoplasmas in southern Brazil. Comp Immunol Microbiol Infect Dis. 2012;37(2012):259-65.

25. Foley JE, Harrus S, Poland A, Chomel B, Pedersen NC. Molecular, clinical, and pathologic comparison of two distinct strains of Haemobartonella felis in domestic cats. Am J Vet Res. 1998;59(12):1581-8.

26. Westfall DS, Jensen WA, Reagan WJ, Radecki SV, Lappin MR. Inoculation of two genotypes of Hemobartonella felis (California and Ohio variants) to induce infection in cats and the response to treatment with azithromycin. Am J Vet Res. 2001;62(5):687-91.

27. Museux K, Boretti FS, Willi B, Riond B, Hoelzle K, Hoelzle LE, et al. In vivo transmission studies of 'Candidatus Mycoplasma turicensis' in the domestic cat. Vet Res. 2009;40(5):45.

28. Tasker S, Peters IR, Papasouliotis K, Cue SM, Willi B, Hofmann-Lehmann R, et al. Description of outcomes of experimental infection with feline haemoplasmas: copy numbers, haematology, Coombs' testing and blood glucose concentrations. Vet Microbiol. 2009;139(3):323-32.

29. Duarte A, Marques V, Correia JHD, Neto I, Bráz BS, Rodrigues C, et al. Molecular detection of haemotropic mycoplasma species in urban and rural cats from Portugal. J Feline Med Surg. 2015;17(6):516-22.

30. Wengi N, Willi B, Boretti FS, Cattori V, Riond B, Meli ML, et al. Real-time PCRbased prevalence study, infection follow-up and molecular characterization of canine hemotropic mycoplasmas. Vet Microbiol. 2008;126(1):132-41.

31. Roura X, Peters IR, Altet L, Tabar M, Barker EN, Planellas M, et al. Prevalence of hemotropic mycoplasmas in healthy and unhealthy cats and dogs in Spain. J Vet Diagn Invest. 2010;22(2):270-4.

32. Kenny MJ, Shaw SE, Beugnet F, Tasker S. Demonstration of two distinct hemotropic mycoplasmas in French dogs. J Clin Microbiol. 2004;42:5397-9.

33. Just F, Pfister K. Detection frequency of haemoplasma infections of the domestic cat in Germany. Berl Munch Tierarztl Wochenschr. 2007; 120(5-6):197-201.

34. Bauer N, Balzer HJ, Thüre S, Moritz A. Prevalence of feline hemotropic mycoplasmas in convenience samples of cats in Germany. J Fel Med Surg. 2008;10(3):252-8.

35. Tasker S, Binns SH, Day MJ, Gruffydd-Jones TJ, Harbour DA, Helps CR, et al. Use of a PCR assay to assess the prevalence and risk factors for Mycoplasma haemofelis and 'Candidatus Mycoplasma haemominutum' in cats in the United Kingdom. Vet Rec. 2003;152(7):193-8.

36. Peters IR, Helps CR, Willi B, Hofmann-Lehmann R, Tasker $S$. The prevalence of three species of feline haemoplasmas in samples submitted to a diagnostics service as determined by three novel real-time duplex PCR assays. Vet Microbiol. 2008;126(1):142-50.

37. Criado-Fornelio A, Martinez-Marcos A, Buling-Saraña A, Barba-Carretero JC. Presence of Mycoplasma haemofelis, Mycoplasma haemominutum and piroplasmids in cats from southern Europe: a molecular study. Vet Microbiol. 2003:93(4):307-17

38. Silaghi C, Knaus M, Rapti D, Kusi I, Shukullari E, Hamel D, et al. Survey of Toxoplasma gondii and Neospora caninum, haemotropic mycoplasmas and other arthropod-borne pathogens in cats from Albania. Parasit Vectors. 2014;7:62.

\section{Submit your next manuscript to BioMed Central and we will help you at every step:}

- We accept pre-submission inquiries

- Our selector tool helps you to find the most relevant journal

- We provide round the clock customer support

- Convenient online submission

- Thorough peer review

- Inclusion in PubMed and all major indexing services

- Maximum visibility for your research

Submit your manuscript at www.biomedcentral.com/submit 